\title{
Application of carbon dioxide to the skin and muscle oxygenation of human lower-limb muscle sites during cold water immersion
}

\author{
Miho Yoshimura ${ }^{1,2}$, Tatsuya Hojo ${ }^{1}$, Hayato Yamamoto ${ }^{1}$, Misato Tachibana ${ }^{1}$, Masatoshi Nakamura ${ }^{3}$, Hiroaki \\ Tsutsumi $^{4,5}$, Yoshiyuki Fukuoka ${ }^{\text {Corresp. } 1}$ \\ ${ }^{1}$ Faculty of Health and Sports Science, Doshisha University, Kyotanabe, Kyoto, Japan \\ 2 Division of Sports Facility Service, Mizuno Corporation, Osaka, Osaka, Japan \\ 3 Department of Physical Therapy, Niigata University of Health and Warfare, Niigata, Niigata, Japan \\ 4 Faculty of Environmental and Symbiotic Science, Prefectural University of Kumamoto, Kumamoto, Kumamoto, Japan \\ 5 Division of eco-Bubble ${ }^{\circledR}$ development, Taikohgiken Itd., Kumamoto, Kumamoto, Japan \\ Corresponding Author: Yoshiyuki Fukuoka \\ Email address: yfukuoka@mail.doshisha.ac.jp
}

Background: Cold therapy has the disadvantage of inducing vasoconstriction in arterial and venous capillaries. The effects of carbon dioxide $\left(\mathrm{CO}_{2}\right)$ hot water depend mainly on not only cutaneous vasodilation but also muscle vasodilation. We examined the effects of artificial $\mathrm{CO}_{2}$ cold water immersion (CCWI) on skin oxygenation and muscle oxygenation and the immersed skin temperature. Subjects and Methods: Fifteen healthy young males participated. $\mathrm{CO}_{2}$-rich water containing $\mathrm{CO}_{2}>1150 \mathrm{ppm}$ was prepared using a microbubble device. Each subject's single leg was immersed up to the knee in the $\mathrm{CO}_{2}$-rich water $\left(20^{\circ} \mathrm{C}\right)$ for $15 \mathrm{~min}$, followed by a 20 -min recovery period. As a control study, a leg of the subject was immersed in cold tap-water at $20^{\circ} \mathrm{C}(\mathrm{CWI})$. The skin temperature at the lower leg under water immersion $\left(\mathrm{T}_{\mathrm{sk}}-\mathrm{WI}\right)$ and the subject's thermal sensation at the immersed and non-immersed lower legs were measured throughout the experiment. We simultaneously measured the relative changes of local muscle oxygenation/deoxygenation compared to the basal values $(\Delta \mathrm{oxy}[\mathrm{Hb}+\mathrm{Mb}], \Delta$ deoxy $[\mathrm{Hb}+\mathrm{Mb}]$, and $\Delta$ total $[\mathrm{Hb}+\mathrm{Mb}])$ at rest, which reflected the blood flow in the muscle, and we measured the tissue $\mathrm{O}_{2}$ saturation $\left(\mathrm{S}_{\mathrm{t}} \mathrm{O}_{2}\right)$ by near-infrared spectroscopy on two regions of the tibialis anterior (TA) and gastrocnemius (GAS) muscles. Results: Compared to the CWI results, the $\Delta o x y[H b+M b]$ and $\Delta$ total $[\mathrm{Hb}+\mathrm{Mb}]$ in the TA muscle at CCWI were increased and continued at a steady state during the recovery period. In GAS muscle, the $\Delta$ total[ $\mathrm{Hb}+\mathrm{Mb}]$ and $\Delta$ deoxy $[\mathrm{Hb}+\mathrm{Mb}]$ were increased during $\mathrm{CCWI}$ compared to CWI. Notably, $\mathrm{S}_{\mathrm{t}} \mathrm{O}_{2}$ values in both TA and GAS muscles were significantly increased during CCWI compared to CWI. In addition, compared to the CWI a significant decrease in $\mathrm{T}_{\mathrm{sk}}$ at the immersed leg after the Peer) reviewing PDF | (2020:01:45095:2:0:NEW 19 Jul 2020) 
CCWI was maintained until the end of the 20 -min recovery, and the significant reduction continued. Discussion: The combination of $\mathrm{CO}_{2}$ and cold water can induce both more increased blood inflow into muscles and volume-related (total heme concentration) changes in deoxy[Hb+Mb] during the recovery period. The $T_{\text {sk }}-W I$ stayed lower with the $\mathrm{CCWI}$ compared to the $\mathrm{CWI}$, as it is associated with vasodilation by $\mathrm{CO}_{2}$. 
1 Original Research

2

3 Application of carbon dioxide to the skin and muscle oxygenation of

$4 \quad$ human lower-limb muscle sites during cold water immersion

6 Miho Yoshimura ${ }^{1,2}$, Tatsuya Hojo ${ }^{1}$, Hyato Yamamoto $^{1}$, Misato Tachibana ${ }^{1}$, Masatoshi Nakamura ${ }^{3}$ Hiroaki

$9{ }^{1}$ Faculty of Health and Sports Science, Doshisha University, Kyoto 610-0394; ${ }^{2}$ Division of Sports Facility

10 Service, Mizuno Corporation, Osaka 581-0822; ${ }^{3}$ Department of Physical Therapy, Niigata University of Health

11 and Warfare, Niigata, 950-3198; ${ }^{4}$ Faculty of Environmental and Symbiotic Science, Prefectural University of

12 Kumamoto, Kumamoto 862-8566; ${ }^{5}$ Division of eco-Bubble ${ }^{\circledR}$ development, Taikohgiken Itd., Kumamoto 860-

13 0047, Japan

15 Running title: $\mathrm{CO}_{2}$ dissolution from skin and muscle blood flow in cold water immersion

18 Corresponding author:

19 Yoshiyuki Fukuoka, PhD,

20 Faculty of Health and Sports Science

21 Doshisha University,

22 3-1 Tatara, Kyotanabe, Kyoto 610-0394, JAPAN

23 tel $+81-774-65-7530$ 
24 fax $+81-774-65-6029$

25 yfukuoka@mail.doshisha.ac.jp 


\section{ABSTRACT}

27 Background: Cold therapy has the disadvantage of inducing vasoconstriction in arterial and venous capillaries. The effects of carbon dioxide $\left(\mathrm{CO}_{2}\right)$ hot water depend mainly on not only cutaneous vasodilation but also muscle vasodilation. We examined the effects of artificial $\mathrm{CO}_{2}$ cold water immersion (CCWI) on skin oxygenation and muscle oxygenation and the immersed

\section{1 skin temperature.}

32 Subjects and Methods: Fifteen healthy young males participated. $\mathrm{CO}_{2}$-rich water containing $\mathrm{CO}_{2}$ $>1150$ ppm was prepared using a micro-bubble device. Each subject's single leg was immersed up to the knee in the $\mathrm{CO}_{2}$-rich water $\left(20^{\circ} \mathrm{C}\right)$ for $15 \mathrm{~min}$, followed by a 20 -min recovery period. As a control study, a leg of the subject was immersed in cold tap-water at $20^{\circ} \mathrm{C}(\mathrm{CWI})$. The skin temperature at the lower leg under water immersion $\left(\mathrm{T}_{\mathrm{sk}}-\mathrm{WI}\right)$ and the subject's thermal sensation at the immersed and non-immersed lower legs were measured throughout the experiment. We simultaneously measured the relative changes of local muscle oxygenation/deoxygenation compared to the basal values $(\Delta \mathrm{oxy}[\mathrm{Hb}+\mathrm{Mb}], \Delta \mathrm{deoxy}[\mathrm{Hb}+\mathrm{Mb}]$, and $\Delta$ total $[\mathrm{Hb}+\mathrm{Mb}])$ at rest, which reflected the blood flow in the muscle, and we measured the tissue $\mathrm{O}_{2}$ saturation $\left(\mathrm{S}_{\mathrm{t}} \mathrm{O}_{2}\right)$ by near-infrared spectroscopy on two regions of the tibialis anterior (TA) and gastrocnemius (GAS)

42 muscles.

Results: Compared to the CWI results, the $\Delta \mathrm{oxy}[\mathrm{Hb}+\mathrm{Mb}]$ and $\Delta$ total $[\mathrm{Hb}+\mathrm{Mb}]$ in the TA muscle at CCWI were increased and continued at a steady state during the recovery period. In GAS muscle, the $\Delta$ total $[\mathrm{Hb}+\mathrm{Mb}]$ and $\Delta$ deoxy $[\mathrm{Hb}+\mathrm{Mb}]$ were increased during $\mathrm{CCWI}$ compared to $\mathrm{CWI}$. Notably, $\mathrm{S}_{\mathrm{t}} \mathrm{O}_{2}$ values in both TA and GAS muscles were significantly increased during CCWI compared to CWI. In addition, compared to the CWI a significant decrease in $\mathrm{T}_{\mathrm{sk}}$ at the immersed leg after the CCWI was maintained until the end of the 20-min recovery, and the significant 49 reduction continued.

50 Discussion: The combination of $\mathrm{CO}_{2}$ and cold water can induce both more increased blood inflow 
51 into muscles and volume-related (total heme concentration) changes in deoxy[Hb+Mb] during the

52 recovery period. The $\mathrm{T}_{\mathrm{sk}}$-WI stayed lower with the CCWI compared to the CWI, as it is associated 53 with vasodilation by $\mathrm{CO}_{2}$. 


\section{INTRODUCTION}

55 Cold therapy has the disadvantage of inducing vasoconstriction in arterial and venous capillaries.

56 The protocols used for cold therapy have involved various combinations of temperatures and

57 durations that were selected based on experience rather than scientific evidence. A review of 58 published protocols indicates that lower water temperature $\left(\leq 15^{\circ} \mathrm{C}\right)$ for durations of $\leq 5 \mathrm{~min}$ have

59 induced many changes in physiological parameters (Šrámek et al. 2000; Bleakley and Davison

60 2010; Ihsan et al. 2016). The physiological mechanisms by which cold water immersion (CWI)

61 influences the body's recovery are not entirely clear (White and Wells 2013), but these mechanisms

62 are likely to be related to effects of the removal of body heat, reduced muscle temperature, and

63 hydrostatic pressure effects rather than to the cold shock response.

64 We have questioned whether CWI therapy requires a water temperature $\leq 15^{\circ} \mathrm{C}$. Similar

65 reductions in femoral artery blood flow were observed in subjects' responses to $8^{\circ} \mathrm{C}$ and $22^{\circ} \mathrm{C}$ 66 cooling at rest (Gregson et al. 2011) and post-exercise (Mawhinney et al. 2013) despite remarkable

67 differences in the muscle temperature. We thus selected the relatively higher temperature of $20^{\circ} \mathrm{C}$

68 for the present study, because a less-noxious cooling temperature that does not cause cold pain

69 (i.e., $>18^{\circ} \mathrm{C}$ ) (Wolf et al. 1941) may provide a suitable alterative for individuals who are unable to

70 tolerate colder temperatures (Gregson et al. 2011). In addition, Proulx et al. (2003) observed an

71 increase in shivering rates in previously hyperthermic individuals when $\mathrm{CWI}$ at $14^{\circ} \mathrm{C}$ was

72 continued beyond $10 \mathrm{~min}$. Indeed, involuntary muscle contraction associated with shivering can

73 increase the body's metabolic rate (Stocks et al. 2004).

74 Over the last three decades, researchers observed that the main effects of immersion in hot water

75 with dissolved carbon dioxide $\left(\mathrm{CO}_{2}\right)$ are cutaneous vasodilation and muscle vasodilation. These

76 effects are elicited by the diffusion of $\mathrm{CO}_{2}$ through the skin layers into the subcutaneous tissues 
77 (Schnizer et al. 1985; Komoto et al. 1986; Ito et al. 1989; Hartmann et al. 1997). We hypothesized 78 that the combined CWI protocol of the relative higher temperature of $20^{\circ} \mathrm{C}$ and longer duration 79 could make it possible for $\mathrm{CO}_{2}$ to overcome the vasoconstriction in arterial and venous capillaries 80 that follows a cold stimulus.

81 Laser Doppler is usually selected for the measurement of the subcutaneous blood (Schnizer et al. 1985; Komoto et al. 1986; Ito et al. 1989; Hartmann et al. 1997), but near-infrared spectroscopy (NIRS) provides a significant amount of precise information on the oxygenation status within 84 small blood vessels and myocytes, including the status of oxygenation (oxy[Hb+Mb]), deoxygenation (deoxy[Hb+Mb]) and their sum, i.e., the total heme (total[Hb+Mb]). NIRS has been used to investigate the blood volume-related changes in the oxy[Hb+Mb], deoxy[Hb+Mb]), and the total $[\mathrm{Hb}+\mathrm{Mb}]$ concentration profiles (Adami et al. 2015; Binzoni et al. 2000; Truijen et al. 2012 ) and/or microvascular $\mathrm{O}_{2}$ extraction (Davies et al. 2008; De Roia et al. 2012; Ferrari et al. 2011). NIRS could thus be useful to determine the effects of $\mathrm{CO}_{2}$ on the changes of microvascular blood flow into skeletal muscles and simultaneously the local metabolism from measurements of the tissue $\mathrm{O}_{2}$ saturation $\left(\mathrm{S}_{t} \mathrm{O}_{2}\right)$ and deoxy $[\mathrm{Hb}+\mathrm{Mb}]$ profile throughout cold immersion and recovery 92 phases.

93 In addition, a customized NIRS device with two additional detector probes can assess the 94 peripheral blood flow in dissociable skin and muscle layers of the tibialis anterior muscle, and its 95 reliability has been validated in both healthy subjects and patients (Ando et al. 2013, Horiuchi et al. 2016; Yamabata et al. 2016). We have therefore attempted to quantify both the skin and muscle

97 blood flow by using this NIRS device in experiments with cold water immersion with enriched $\mathrm{CO}_{2}$ (CCWI). However, it has been unclear whether combined $\mathrm{CO}_{2}$ and cold water would 99 influence both skin and muscle blood perfusion, due to the complexity of various physiological 
100 actions (e.g., $\mathrm{CO}_{2}$-induced vasodilation, a cold stimulus, and hydrostatic pressure). Thus, our first

101 hypothesis was that the use of $\mathrm{CO}_{2}$ can overcome the vasoconstriction in arterial and venous

102 capillaries due to a cold stimulus at $20^{\circ} \mathrm{C}$ and that consequently, the augmented heat transfer from

103 the body to the water using $\mathrm{CO}_{2}$ could lead to decreased skin temperature during CCWI compared 104 to CWI.

105 Our second hypothesis was that the arterial and venous vasodilation in both superficial and 106 muscle layers of different muscles would be significantly augmented by enriched $\mathrm{CO}_{2}$, even

107 though during CWI a cold stimulus induces vasoconstriction. We conducted the present study to 108 test these two hypotheses.

109

110 SUBJECTS AND METHODS

\section{Subjects' characteristics}

112 We recruited 15 healthy young male subjects (age $23.1 \pm 0.4 \mathrm{yrs}$, weight $61.4 \pm 1.8 \mathrm{~kg}$, height

$113171 \pm 1.4 \mathrm{~cm}$, mean \pm SE) for the study. The subjects' body mass index (BMI) values and body fat

114 percentage were $20.8 \pm 0.5$ and $15.7 \pm 1.1 \%$, respectively. Written informed consent was obtained

115 from all subjects after they received a detailed explanation about all procedures, the purpose of the

116 study, and the possible risks and benefits of their participation. This study conformed to the

117 Declaration of Helsinki, and the Ethics Committee of Doshisha University approved the purpose 118 and all procedures of the study (no. 15085). None of the subjects had cardiovascular abnormalities 119 or skin lesions.

\section{Water immersion protocol}

122 All of the experiments were performed at the same time of the day in a climatic chamber with its 
123 ambient temperature and relative humidity maintained at $25.0 \pm 0.5^{\circ} \mathrm{C}$ and $55 \pm 3 \%$, respectively.

124 After entering the climatic chamber, the subject assumed a sitting position on a chair for 10 min

125 (rest stage) and then immersed his right lower leg up to the knee in a 47-L water container for 15

126 min in $\mathrm{CO}_{2}$-rich water (1150 ppm, CCWI) or tap water (CWI) maintained at $20^{\circ} \mathrm{C}$ (Fig. 1). After

127 the 15-min immersion, the subject withdrew his lower leg from the CCWI or CWI and then rested

128 for a 20-min recovery period. The subjects performed both a CWI and a CCWI and were not

129 informed whether the water was CCWI or CWI in order to ensure a double-blind design.

130 The $\mathrm{CO}_{2}$-rich water was prepared by dissolving $\mathrm{CO}_{2}$ in tap water using a dual-chamber/dual-

131 vortex high speed rotation system (DDHRS; type S1, Taikougiken, Kumamoto, Japan). Water was

132 pumped into the DDHRS. Gas was injected into the DDHRS and was reduced in the DDHRS by

133 the centrifugation effect. In this study, the flow rates of $\mathrm{CO}_{2}$ and water were $0.3 \mathrm{~L} / \mathrm{min}$ and 20

$134 \mathrm{~L} / \mathrm{min}$, respectively. This DDHRS can produce a microbubble water flow in which $\mathrm{CO}_{2}$ is

135 dissolved very quickly (within $10 \mathrm{~min}$ ) by a connection with a small $\mathrm{CO}_{2}$ cartridge $(74 \mathrm{~g}$ ), and the

136 temperature was maintained at $20^{\circ} \mathrm{C}$ by an isothermal cooling system (BB310, Yamato, Shiga,

137 Japan).

138

139 Measurements and data analysis

140 As the subjects' core temperature $\left(\mathrm{T}_{\text {core }}\right)$, the sublingual temperature was measured with an electric

141 thermometer (MC-652LC, Omron, Kyoto, Japan). Two skin temperatures were measured at the

142 lower leg (i.e., the tibialis anterior [TA] muscle) under water immersion $\left(\mathrm{T}_{\mathrm{sk}}-\mathrm{WI}\right)$ and at the

143 subject's non-immersed control leg ( $\mathrm{T}_{\mathrm{sk}}$-cont) with commercial thermistors (LT-8, Gram Co.,

144 Saitama, Japan). The thermistors for the lower legs were positioned at the point at one-third of the

145 length of the lateral epicondyle of the femur and the malleolus lateralis line from the lateral 
146 epicondyle of the femur and the same length horizontally back.

147 At the same time as the temperature measurements, the subject's systolic and diastolic blood

148 pressure (SBP, DBP) and heart rate (HR) were recorded by an automated tonometer technique

149 (HBP-1300, Omron) using the subject's upper right arm which rested at heart level alongside his

150 body. The mean arterial pressure (MAP) was automatically calculated with the formula MAP =

$151 \mathrm{DBP}+1 / 3(\mathrm{SBP}-\mathrm{DBP})$.

152 The subject's thermal sensation was reported by the subject every 5 min after the start of the pre-

153 immersion and throughout the experiment. The thermal sensations were rated by the subject based

154 on a conventional seven-point scale (IOS-7730 1984) comprising cold (-3), cool (-2), slightly

$155 \operatorname{cool}(-1)$, neutral (0), slightly warm (1), warm (2), and hot (3). In this study, we limited the thermal

156 sensations to a narrow scale: below -3 to 0 .

157 We measured each subject's skin adipose tissue thickness (ATT) on two regions of the TA and 158 gastrocnemius (GAS) muscles by using an ultrasonic device (SSD-3500SV, Hitachi-Aloka 159 Medical, Tokyo), because the transmissive pulsed light in the NIRS device is influenced by the 160 ATT when the ATT is $>5 \mathrm{~mm}$ in both of the two muscle regions (Binzoni et al. 1998).

161 NIRS provides a noninvasive window into the microvascular and intramuscular oxygenation 162 status of skeletal muscle under a wide range of conditions at rest (Adami et al. 2015; Binzoni et 163 al. 2000) and during exercise (Koga et al. 2013). In healthy and clinical populations, the total heme 164 concentration (total $[\mathrm{Hb}+\mathrm{Mb}])$ and the tissue $\mathrm{O}_{2}$ saturation $\left(\mathrm{StO}_{2}\right)$ can be estimated (Yamabata et 165 al. 2016). In the present study, the oxygenation (oxy[Hb+Mb]) and deoxygenation $166(\mathrm{deoxy}[\mathrm{Hb}+\mathrm{Mb}])$ concentration profiles and their sum (i.e., the total $[\mathrm{Hb}+\mathrm{Mb}]$ concentration 167 profile) on the two regions of the TA and GAS muscles were simultaneously recorded by two 168 customized continuous-wave NIRS devices (BOM-L1 TR, Omega Wave Co., Tokyo). This system 
169 was able to continuously monitor the changes in the oxy[Hb+Mb], deoxy[Hb+Mb], and

170 total $[\mathrm{Hb}+\mathrm{Mb}]$ concentrations at two different sites (the skin and muscle). Data were collected as

171 previously described in Yamabata (2016). Specifically, we calculated from the light attenuation

172 changes by using a modification of the Beer-Lambert law.

173 In this study, we defined the 7.5-mm layer as 'superficial' and the 15-mm layer as 'muscle.' The

174 TA and GAS muscles with the attached probe holder were then wrapped in a dark-colored elastic

175 bandage to further secure the probes and to eliminate ambient light that might contaminate the

176 NIRS signals. The NIRS data reflected the relative concentration changes in the hemoglobin

177 chromophores and thus did not reflect the absolute tissue $\mathrm{O}_{2}$ values. As we set the probe gain

178 setting at 0 prior to testing the subjects at rest in the sitting position, the relative changes from the

179 resting $(\Delta \mathrm{oxy}[\mathrm{Hb}+\mathrm{Mb}], \Delta$ deoxy $[\mathrm{Hb}+\mathrm{Mb}]$, and $\Delta$ total $[\mathrm{Hb}+\mathrm{Mb}])$ values were calculated. With the

180 use of two detectors at the lower penetration depth of $7.5 \mathrm{~mm}$, the superficial $\Delta \mathrm{oxy}[\mathrm{Hb}+\mathrm{Mb}]$,

$181 \Delta$ deoxy $[\mathrm{Hb}+\mathrm{Mb}]$, and $\Delta \operatorname{total}[\mathrm{Hb}+\mathrm{Mb}]$ values were assumed to reflect the cutaneous blood flow

182 (i.e., $\Delta$ oxy $[\mathrm{Hb}+\mathrm{Mb}]_{\text {superficial, }} \Delta$ deoxy $[\mathrm{Hb}+\mathrm{Mb}]_{\text {superficial, }}$ and $\Delta$ total $[\mathrm{Hb}+\mathrm{Mb}]_{\text {superficial }}$ ).

183 We also measured the data from the deep penetration depth of $15 \mathrm{~mm}$ (i.e., the muscle $184 \Delta$ oxy $[\mathrm{Hb}+\mathrm{Mb}], \quad \Delta$ deoxy $[\mathrm{Hb}+\mathrm{Mb}], \quad$ and $\Delta$ total $[\mathrm{Hb}+\mathrm{Mb}])$ values. The $\Delta$ oxy $[\mathrm{Hb}+\mathrm{Mb}]_{\text {muscle }}$,

$185 \Delta$ deoxy $[\mathrm{Hb}+\mathrm{Mb}]_{\text {muscle, }}$ and $\Delta$ total $[\mathrm{Hb}+\mathrm{Mb}]_{\text {muscle }}$ were obtained by subtracting these superficial

186 variables from the muscle variables $\left(\Delta \mathrm{oxy}[\mathrm{Hb}+\mathrm{Mb}]_{\text {muscle}}, \Delta\right.$ deoxy $[\mathrm{Hb}+\mathrm{Mb}]_{\text {muscle, }}$ and

$187 \Delta$ total $[\mathrm{Hb}+\mathrm{Mb}]_{\text {muscle }}$ according to the modified Beer-Lambert law (Ando et al. 2013, Horiuchi et

188 al. 2016; Yamabata et al. 2016).

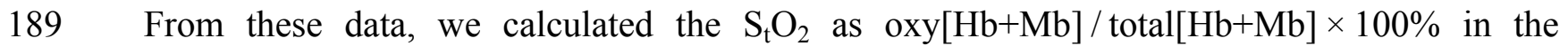

190 superficial and muscle regions. The NIRS-S $\mathrm{O}_{2}$ measurements reflect a mixture of arteriole,

191 capillary, and venous blood flows and do not separate venous from arterial saturations (Culver 
192 2003). NIRS-derived $\mathrm{S}_{\mathrm{t}} \mathrm{O}_{2}$ values closely correspond to the actual microvascular oxygenation in

193 skeletal muscle $\left(\mathrm{S}_{\mathrm{m}} \mathrm{O}_{2}\right)$ (Koga et al. 2013; Sperandio et al. 2009; Wust et al. 2014).

194 We calculated the averaged data of each NIRS parameter for $30 \mathrm{sec}$ at each 3-min interval

195 throughout the experiment: water immersion (WI)3 through WI15 at 3, 6, 12, and 15 min, and

196 recovery (rec)3 through rec18 at 3, 6, 12, 15, and $18 \mathrm{~min}$. The baseline values were averaged for

197 the final $30 \mathrm{sec}$ of the subject's 10-min rest in a sitting position. The data of the cardiovascular

198 indexes were calculated at each 5-min interval, i.e., baseline; 10-min sitting position; the rest

199 periods, WI for $15 \mathrm{~min}$ (WI5, WI10, and W15), and recovery for $20 \mathrm{~min}$ (rec5, rec10, rec15, and

200 rec20), averaging the values for $30 \mathrm{sec}$ at each period.

201

202 Statistical analysis

203 All values are presented as the mean \pm standard error (SE). The significance of differences in each

204 variable $(\Delta \mathrm{oxy}[\mathrm{Hb}+\mathrm{Mb}], \Delta$ deoxy $[\mathrm{Hb}+\mathrm{Mb}]$, and $\Delta$ total $[\mathrm{Hb}+\mathrm{Mb}])$ was determined by a two-way 205 analysis of variance (ANOVA) comparing water conditions $(\mathrm{CCWI}$ and CWI) $\times$ time periods (rest, WI3-WI15, and recovery at rec3-rec18). A post hoc comparison was applied by Bonferroni test

207 for the appropriate data sets when a significant $F$-value was obtained. A partial eta-square $\left(\eta^{2}\right)$ was 208 also determined. Another post hoc comparison was applied by Dunnett's test to determine multiple comparisons from baseline. All analyses were performed using SPSS software (Abacus Concepts, Berkeley, CA) with significance in all cases set at the 5\% level.

211 Regarding the sample determination using PS Power and Sample Size Calculations (Dupont and

212 Plummer 1998), we are planning a study of a continuous response variable from matched pairs of

21315 healthy young subjects. Prior data of $\Delta \mathrm{StO}_{2}$ of TA and GAS muscles indicate that the difference

214 in the response of matched pairs is normally distributed with the standard deviation 3.486. If the 
215 true difference in the mean response of matched pairs is 3.9 , we will need to study 8 pairs of

216 subjects to be able to reject the null hypothesis that this response difference is zero with the

217 probability (power) 0.8 . The Type I error probability associated with this test of the null hypothesis

218 is 0.05 . Therefore, judging from the criteria of the power 0.8 , we recognized that the sample size

219 of our 15 pairs of subjects provides the power 0.941.

220

221 RESULTS

222 The ATT findings

223 The average ATT value in the TA region was $3.0 \pm 0.2 \mathrm{~mm}$, and that in the GAS region was $3.9 \pm 0.3$

$224 \mathrm{~mm}$.

225

226 Cardiovascular responses during water immersion

227 The 15 subjects' MAP values remained unchanged during the immersion and recovery periods,

228 with no significant difference between CCWI and CWI (interaction effect: $F(9,126)=0.892$,

$229 \mathrm{p}=0.534$ ) (Fig. 2A). As shown in Figure 2B, the HR values during the CCWI remained constant

230 throughout the experiment $\left(74 \pm 2.2\right.$ beats $\min ^{-1}$ at baseline and $\mathrm{WI} 15 ; 73 \pm 2.3$ beats $\min ^{-1}$ at rec 20$)$

231 (interaction effect: $\mathrm{F}(9,126)=0.446, \mathrm{p}=0.908)$, which supported the idea that the diving reflex in

232 HR could not be induced with only one leg immersed in the water. These results indicate that both

233 the cold $\mathrm{CO}_{2}$-rich water and cold tap water immersions themselves did not influence the subjects'

234 cardiovascular responses during one-leg water immersion, irrespective of the $\mathrm{CO}_{2}$ condition.

235

236 Core temperature and skin temperatures in the WI and non-WI legs during $\mathrm{CO}_{2}$-rich

237 immersion and recovery 
238 The sublingual temperature $\left(\mathrm{T}_{\text {core }}\right)$ values during the CCWI remained constant at a narrow range

239 between $36.4^{\circ}$ and $36.6^{\circ} \mathrm{C}$ and were not significantly lower than those during the CWI (Fig.

2402 2)(interaction effect: $\mathrm{F}(9,126)=1.131, \mathrm{p}=0.346)$. The $\mathrm{T}_{\text {sk }}$-WI values decreased abruptly during

241 each water immersion (CCWI: $21.8 \pm 0.1^{\circ} \mathrm{C}, \mathrm{CWI}: 21.8 \pm 0.2^{\circ} \mathrm{C}$, at WI15) and returned at the end of

242 the recovery, i.e., $\operatorname{rec} 18$ (CCWI: $25.8 \pm 0.2^{\circ} \mathrm{C}$, CWI: $26.4 \pm 0.2^{\circ} \mathrm{C}$ ) (Fig. $3 \mathrm{~A}$ ).

243 Compared to the baseline, there was significant lower $\mathrm{T}_{\mathrm{sk}}$-WI during the CCWI and CWI until

244 the end of recovery (time effect: $F(1,154)=446.973, p<0.001, \eta^{2}=0.970$ ). Compared to the CWI,

245 the significantly lower $\mathrm{T}_{\mathrm{sk}}$-WI values continued from rec9 to rec18 of the recovery period

246 following the CCWI (interaction effect: $\mathrm{F}(11,154)=1.901, \mathrm{p}=0.048, \eta^{2}=0.160$ ). In addition, the

$247 \mathrm{~T}_{\mathrm{sk}}$-cont values gradually and significantly decreased from baseline to rec 18 and were significantly

248 lower from WI9 during the CCWI and from WI15 during the CWI to rec18 (time effect:

$249 F(1,154)=19.445, p<0.001, \eta^{2}=0.599$, Fig. 3B).

250 It is very noteworthy that the control leg ( $\mathrm{T}_{\mathrm{sk}}$-cont) values tended to be lower during the CCWI

251 than during the CWI until the end of recovery, corresponding to the reduction in $\mathrm{T}_{\mathrm{sk}}-\mathrm{WI}$. In

252 addition, the thermal sensation was significantly decreased during the immersion and began

253 increasing again during the recovery period (Fig. 2D) (time effect: $F(1,126)=8.985, p<0.001$,

$254 \eta^{2}=0.391$ ), but it was slightly lower at a later recovery point in the CCWI compared to the CWI

255 (condition effect: $\mathrm{F}(1,14)=0.440, \mathrm{p}=0.518$ ).

256

257 TA muscle

258 The $\Delta \mathrm{oxy}[\mathrm{Hb}+\mathrm{Mb}]_{\text {superficial }}$ increased significantly from baseline (by approx. $0.2 \mathrm{AU}$ ) during the

259 CCWI (periods WI3 to rec3, $\mathrm{p}<0.01$ ) and the CWI (periods WI9 to WI12, $<<0.01$ ), and this

260 response returned to baseline following the water immersion (time effect: $\mathrm{F}(11,143)=14.076$, 
$261 \mathrm{p}<0.001, \eta^{2}=0.573$, Fig. 4A). The $\Delta$ deoxy $[\mathrm{Hb}+\mathrm{Mb}]_{\text {superficial }}$ during the CCWI remained constant

262 until the end of the water immersion, and it was significantly increased at rec15 and rec18 from

263 baseline due to vasodilation in venous veins during recovery (time effect: $\mathrm{F}(11,143)=5.087$,

$264 \mathrm{p}<0.001, \eta^{2}=0.298$, Fig. 4B). The $\Delta$ total $[\mathrm{Hb}+\mathrm{Mb}]_{\text {superficial }}$ increased by approx. 0.2 AU during water

265 immersion and stayed higher during the recovery following immersion (time effect: $F(11$,

$266143)=1.763, p=0.066$, Fig. $4 \mathrm{C})$. Overall, the increase in $\Delta$ total $[\mathrm{Hb}+\mathrm{Mb}]_{\text {superficial }}$ was a result of the

$267 \Delta \mathrm{oxy}[\mathrm{Hb}+\mathrm{Mb}]_{\text {superficial }}$ increase during water immersion, and during recovery this response was a

268 result of the $\Delta$ deoxy $[\mathrm{Hb}+\mathrm{Mb}]_{\text {superficial }}$ increase.

269 The $\Delta$ oxy $[\mathrm{Hb}+\mathrm{Mb}]_{\text {muscle }}$ increased gradually from baseline and stayed at a higher level during

270 the recovery period with a moderate ES at all points between CCWI and CWI (ES: 0.67-0.80,

271 interaction effect: $F(11,143)=1.813, \mathrm{r}=0.060$, Fig. 4D). By contrast, the $\Delta$ deoxy $[\mathrm{Hb}+\mathrm{Mb}]_{\text {muscle }}$

272 was unaltered from baseline and increased slightly after the CCWI (Fig. 4E). The

$273 \Delta$ total $[\mathrm{Hb}+\mathrm{Mb}]_{\text {muscle }}$ consequently and gradually increased until the end of recovery without a

274 significant increase from baseline, and this trend contributed mostly to the $\Delta \mathrm{oxy}[\mathrm{Hb}+\mathrm{Mb}]_{\text {muscle }}$

275 response with a significant difference at some time points during the CCWI compared to the CWI

276 (interaction effect: $F(11,143)=1.983, p=0.044, \eta^{2}=0.161$, Fig. 4F).

277

278 GAS muscle

279 In the CCWI protocol, the $\Delta \mathrm{oxy}[\mathrm{Hb}+\mathrm{Mb}]_{\text {superficial }}$ was increased from baseline and gradually 280 decreased to below the baseline after immersion (Fig. 5A). Notably, the $\Delta$ oxy[Hb+Mb $]_{\text {superficial }}$ was

281 significantly elevated from baseline (time effect: $F(11,143)=9.258, p<0.001, \eta^{2}=0.416$ ). By

282 contrast, the $\Delta$ deoxy $[\mathrm{Hb}+\mathrm{Mb}]_{\text {superficial }}$ during the water immersion abruptly decreased to a 283 significantly lower level from baseline in both the CCWI and CWI (time effect: F(11, 
$284143)=24.118, \mathrm{p}<0.001, \eta^{2}=0.650$ ) and increased again during recovery (interaction effect:

$285 \mathrm{~F}(11,143)=2.107, \mathrm{p}=0.023, \eta^{2}=0.139$, Fig. $\left.5 B\right)$. During the CCWI, the $\Delta$ total $[\mathrm{Hb}+\mathrm{Mb}]_{\text {superficial }}$

286 tended to be lower than the baseline values, but this decrease was sustained below baseline until

287 the end of recovery (Fig. 5C).

288 At the GAS muscle region, the $\Delta \mathrm{oxy}[\mathrm{Hb}+\mathrm{Mb}]_{\text {muscle }}$ was constant throughout the CCWI. After 289 the $\mathrm{CWI}, \Delta \mathrm{oxy}[\mathrm{Hb}+\mathrm{Mb}]_{\text {muscle }}$ gradually decreased until the end of recovery (time effect: $\mathrm{F}(11$, $290143)=6.602, \mathrm{p}<0.001, \eta^{2}=0.355$, Fig. 5D). The $\Delta$ deoxy $[\mathrm{Hb}+\mathrm{Mb}]_{\text {muscle }}$ was gradually augmented 291 until the end of recovery (time effect: $F(11,143)=8.875, p<0.001, \eta^{2}=0.425$, Fig. 4E), which 292 reflected mostly the $\Delta \operatorname{total}[\mathrm{Hb}+\mathrm{Mb}]_{\text {muscle }}$ response (Fig. $5 \mathrm{~F}$ ). By contrast, the $\Delta$ total $[\mathrm{Hb}+\mathrm{Mb}]_{\text {muscle }}$ 293 showed the following: a decrease of $\Delta \mathrm{oxy}[\mathrm{Hb}+\mathrm{Mb}]_{\text {muscle }}$ and an increase of $\Delta$ deoxy $[\mathrm{Hb}+\mathrm{Mb}]_{\text {muscle }}$ 294 that offset each other.

295

296 Alternations in $\mathbf{O}_{2}$ saturation inmuscle as measured by NIRS

297 The $\mathrm{StO}_{2}$ values gradually increased during the water immersion and then returned to a decrease 298 during the recovery period (Suppl. Table). At the 20-min recovery, the $\mathrm{StO}_{2}$ values had fallen to 299 below the baseline. Since the baseline values of $\mathrm{StO}_{2}$ differed between the CCWI and CWI, we 300 estimated the change in the $\mathrm{StO}_{2}$ from baseline $\left(\Delta \mathrm{StO}_{2}\right)$ to compare the values between the CCWI 301 and CWI and between the TA and GAS muscles (Fig. 6). For the TA muscle, a significant increase 302 from baseline in $\Delta \mathrm{StO}_{2 \text { muscle }}$ reached $7.5 \pm 1.1 \%$ at WI9 in the CCWI (time effect: $\left.303 \mathrm{~F}(11,143)=17.025, \mathrm{p}<0.001, \eta^{2}=0.654\right)$, which was very similar to the $\Delta \mathrm{StO}_{2 \text { superfical }}$ value $3048.0 \pm 0.9 \%$. It is therefore likely that the $\mathrm{CO}_{2}$ diffusion arrives at deep muscle tissue in the TA. By

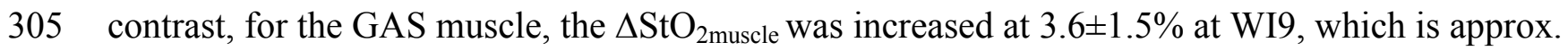
306 one-half compared to the $\Delta \mathrm{StO}_{2 \text { superfical }}$ of $7.5 \pm 0.9 \%$ at WI9; this suggests that it might be difficult 
307 for $\mathrm{CO}_{2}$ to diffuse into the GAS. Apparently, $\mathrm{CO}_{2}$ induced a greater $\Delta \mathrm{StO}_{2}$ in both superficial and

308 muscle regions in both the TA and GAS (interaction effect: $p=0.044-0.002, \eta^{2}=0.61-0.251$ ).

309

310 DISCUSSION

311 Using NIRS, we examined two common assumptions regarding the application of $\mathrm{CO}_{2}$-rich cold

312 water immersion (CCWI) to (1) the changes in skin and muscle blood perfusion related to

313 capillary-venous heme concentration and the volume of small vessels, and (2) the promotion of

314 the heat transfer from the body to the water due to vasodilation during CCWI. To examine these

315 assumptions, we first used a resting cold water immersion protocol to determine the agreement

316 between $\mathrm{CO}_{2}$-induced vasodilation and the change in leg skin temperature. Our results indicate

317 that during the recovery period after water immersion, the heat dissipation could be promoted by

318 using CCWI rather than CWI, because a significantly lower $\mathrm{T}_{\mathrm{sk}}$-WI continued until the end of the

319 recovery period. The NIRS profiles of the oxy $[\mathrm{Hb}+\mathrm{Mb}]_{\text {superficial }}$ responses in both the TA and GAS

320 muscles may also support the concept that CCWI in greater increases of cutaneous blood flow and

321 blood volume with different $\Delta$ deoxy $[\mathrm{Hb}+\mathrm{Mb}]_{\text {superficial }}$ values.

322 In addition, we assessed whether $\Delta$ deoxy $[\mathrm{Hb}+\mathrm{Mb}]_{\text {muscle }}$ was not affected by the changes in

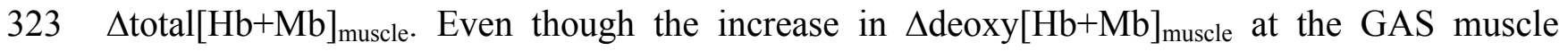

324 contributed to the $\Delta \operatorname{total}[\mathrm{Hb}+\mathrm{Mb}]_{\text {muscle }}$ during water immersion, we also observed that the increase

325 in $\Delta$ deoxy $[\mathrm{Hb}+\mathrm{Mb}]_{\text {muscle }}$ corresponded to the increase in $\Delta$ total $[\mathrm{Hb}+\mathrm{Mb}]_{\text {muscle }}$ during the recovery

326 period irrespective of different muscles or muscle layers. It is difficult to comprehensively interpret

327 our results in part due to the complexity of three interactive factors of cold stimulus, hydrostatic

328 pressure, and $\mathrm{CO}_{2}$ vasodilation effects. We should thus take into account that two separate periods

329 between water immersion and recovery may be altered by different physiological mechanisms. 
$331 \mathrm{CO}_{2}$ promotes more the heat transfer from the body to the water and lower skin temperature

332 during CCWI than CWI.

333 Our analyses revealed that compared to the CWI, the CCWI induced a slightly lower $\mathrm{T}_{\mathrm{sk}}$-WI and

334 a slightly higher thermal sensation at the recovery period, which indicates that CCWI facilitates

335 not only a decline in $\mathrm{T}_{\mathrm{sk}}$-WI but also a less cold sensation following water immersion. These

336 observations confirm that an increase in cutaneous blood flow during CCWI may elicit excess heat

337 transfer even if the water temperature is cool. $\mathrm{CO}_{2}$ applied topically can increase the cutaneous

338 blood flow (Diji 1959; Komoto et al. 1986; Ito et al. 1989; Hartmann et al. 1997) due to cutaneous

339 vasodilation (Ito et al. 1989). In the present investigation, this effect promoted not only the heat

340 transfer from the body to the water and lower $\mathrm{T}_{\text {sk }}$-WI values; it also produced lower $\mathrm{CO}_{2}$-induced

$341 \mathrm{~T}_{\mathrm{sk}}$-cont values, which is one of the strong countermeasures of a hot environment in sports.

342 Moreover, compared to the CWI, the CCWI facilitated the slightly lower cold sensation. It has

343 been demonstrated that $\mathrm{CO}_{2}$ inhibits the activity of cold receptors and facilitates the activity of

344 warm receptors of the skin (Dodt 1956). Such modifications in the activity of skin receptors by

$345 \mathrm{CO}_{2}$ can explain the elevation of the thermal sensations that we observed during the CCWI

346 compared to the CWI, since thermal sensations are caused predominantly by the signals from skin

347 receptors rather than central receptors (Hensel 1981).

348 We set the water temperature at $20^{\circ} \mathrm{C}$ because cold receptors are discharged most vigorously at

349 skin temperatures at $25^{\circ} \mathrm{C}$ (Tansey and Johnson 2015) and cold immersion even at $20^{\circ} \mathrm{C}$ in this

350 study would have excited a greater number of stimulated cold receptors. In a review of CWI

351 studies, a water temperature at $\sim 14^{\circ} \mathrm{C}$ was most commonly selected with a $\leq 15$-min immersion

352 duration (Choo et al. 2018a). We selected $20^{\circ} \mathrm{C}$ with a longer immersion duration (15 min) for the 
353 present experiment, and the $\mathrm{T}_{\mathrm{sk}}-\mathrm{WI}$ was reduced from $31.8 \pm 0.2^{\circ} \mathrm{C}$ to $21.8 \pm 0.1^{\circ} \mathrm{C}$ at the end of the

354 immersion, indicating that the underlying muscles were probably cooled to a significant degree

355 and to the same extent between CCWI and CWI (Ihsan et al. 2013).

356 We expected that in the CCWI, increased cutaneous blood flow due to cutaneous vasodilation

357 via $\mathrm{CO}_{2}$ would facilitate the heat transfer from the subject's body to the water. Indeed, an increased

$358 \Delta \mathrm{oxy}[\mathrm{Hb}+\mathrm{Mb}]_{\text {superficial }}$ was observed even during the CCWI. Consequently, the

$359 \Delta \operatorname{total}[\mathrm{Hb}+\mathrm{Mb}]_{\text {superficial }}$ at the TA muscle tended to be higher than the baseline (time effect:

$360 \mathrm{p}=0.066$ ), and fell significantly from the baseline in the GAS muscle (time effect: $\mathrm{p}=0.027$ ). Our

361 NIRS results thus support our hypothesis that CCWI depresses the marked reduction in the

362 cutaneous blood flow.

363

364 The impact of hydrostatic pressure during water immersion leads to inflow into muscle.

365 Hydrostatic pressure might reduce edema and inflammation by increasing the pressure gradient

366 between the interstitial and intravascular spaces, promoting the re-absorption of interstitial fluid in

367 a manner similar to compression stockings (Partsch et al. 2004). The combination of a cold

368 stimulus and hydrostatic pressure could also act synergistically; decreased muscle temperature

369 may reduce edema by reducing the muscle perfusion (cold-induced vasocontraction) and fluid

370 diffusion into the interstitial space (Yanagisawa and Fukubayashi 2010; Gregson et al. 2011), as

371 well as through a reduced permeability of cellular, lymphatic, and capillary vessels (Cote et al.

372 1988). This might complement any hydrostatic pressure effects on interstitial-intravascular fluid 373 movement.

374 In the present study, the $\Delta \mathrm{oxy}[\mathrm{Hb}+\mathrm{Mb}]_{\text {muscle }}$ gradually increased from baseline and stayed at a

375 relatively higher level during recovery. Overall, the increase in $\Delta \operatorname{total}[\mathrm{Hb}+\mathrm{Mb}]_{\text {muscle }}$ in the TA 
376 muscle was a result of the $\Delta \mathrm{oxy}[\mathrm{Hb}+\mathrm{Mb}]_{\text {muscle }}$ increase during the CCWI, and this response was a

377 result of both the $\Delta \mathrm{oxy}[\mathrm{Hb}+\mathrm{Mb}]_{\text {muscle }}$ and $\Delta$ deoxy $[\mathrm{Hb}+\mathrm{Mb}]_{\text {muscle }}$ during the recovery period. Choo

378 et al. (2018b) reported that the skin blood flow had notably less influence on the total[Hb+Mb]

379 signal during the recovery after cooling compared to a non-cooling recovery. However, our

380 findings regarding the $\Delta \operatorname{total}[\mathrm{Hb}+\mathrm{Mb}]_{\text {muscle }}$ kinetics differed, and they indicate that $\mathrm{CO}_{2}$ could

381 influence the muscle blood flow increase.

382 By contrast, in the GAS muscle in the CCWI, the $\Delta \mathrm{oxy}[\mathrm{Hb}+\mathrm{Mb}]_{\text {muscle }}$ remained unchanged

383 throughout the experiment. The gradually augmented $\Delta$ deoxy $[\mathrm{Hb}+\mathrm{Mb}]_{\text {muscle }}$ values were mostly

384 reflected by the $\Delta \operatorname{total}[\mathrm{Hb}+\mathrm{Mb}]_{\text {muscle }}$ response. The results of several intervention studies suggest

385 that the deoxy $[\mathrm{Hb}+\mathrm{Mb}]_{\text {muscle }}$ profile is likely to have different effects on the $\mathrm{O}_{2}$ extraction-related

386 changes and volume-related changes (Adami et al. 2015; Binzoni et al. 2000; Truijen et al. 2012).

387 Thus, CCWI intervention without shivering would improve the redistribution of blood flow from

388 the non-immersion site to the immersion site. If the $20^{\circ} \mathrm{C}$ cold exposure reduces the metabolic

389 demand, an abrupt decline in the $\Delta$ deoxy $[\mathrm{Hb}+\mathrm{Mb}]_{\text {muscle }}$ from baseline would occur; however, the

390 above result indicated no decline of the $\Delta$ deoxy $[\mathrm{Hb}+\mathrm{Mb}]_{\text {muscle }}$ in the TA or GAS muscles.

391

392 Different oxygenation in the TA and GAS regions during water immersion

393 We observed significant increases in the $\Delta \mathrm{StO}_{2}$ in both the TA and GAS muscles during the CCWI

394 (time effect: $\mathrm{p}<0.001$ ). Apparently, $\mathrm{CO}_{2}$ induced a greater $\Delta \mathrm{StO}_{2}$ in both superficial and muscle

395 regions in both the TA and GAS. However, for the TA muscle, there was a similar increase from

396 the baseline in the $\Delta \mathrm{StO}_{2}$ between the skin layer and muscle layer during the CCWI. By contrast,

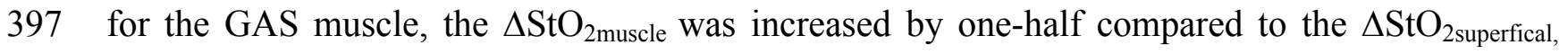

398 suggesting that it might be difficult for $\mathrm{CO}_{2}$ to diffuse into the GAS. It may be possible that specific 
399 characteristics of TA muscle account for muscle fiber-type-dependent muscle oxygenation

400 responses to a combined cold and $\mathrm{CO}_{2}$ stimulus, because $>70 \%$ of the TA muscle in humans

401 consists of only slow-twitch fibers (Dahmane et al. 2005). Slow-twitch fibers have more developed

402 muscle capillaries than fast-twitch fibers, which means that the vasodilatory effect of $\mathrm{CO}_{2}$ is further 403 improved.

405 Underlying mechanism of vasodilation during $\mathrm{CO}_{2}$ water immersion

406 A plausible mechanism of $\mathrm{CO}_{2}$-induced vasodilation is associated with extracellular acidosis.

407 Traditional studies demonstrated that acidosis might reduce the contractility of the vascular smooth 408 muscle, leading to vasodilation (Tobian et al. 1959; Vanhoutte and Clement 1968). The reduction 409 in smooth muscle contractility has been ascribed to a reduction in calcium influx or to the 410 suppression of myofilament contractility (Breemen et al. 1972; Fabiato and Fabiato 1978). An in

411 vitro study examining the contractility of the rat aorta exposed to a small change in $\mathrm{pH}$ (from 7.4

412 to 7.0 ) demonstrated that even this small change in $\mathrm{pH}$ could reduce vascular smooth muscle

413 contractility (Loutzenhiser et al. 1990). That study also indicated that $\mathrm{H}^{+}$-induced vasodilation is

414 associated with an increase in the amount of calcium sequestered in the norepinephrine-sensitive 415 intracellular calcium store.

416 Other investigations of the coronary, cerebral and aortic circulations have shown that nitric 417 oxide (Fukuda et al. 1990; Gurevicius et al. 1995; Aalkjær and Peng 1997) and the activation of 418 potassium channels (Ishizaka and Kuo 1996) may contribute to this acidosis-induced vasodilation.

419 Both skin and muscle arterioles are known to be regulated by sympathetic outflow and vasodilatory 420 substances such as nitric oxide (Hickner 1997; Kellogg 2006; Bernjak 2012). However, we did not 421 measure the blood substances of $\mathrm{pH}$, potassium, or nitric oxide or their underlying mechanisms in 
422 this study.

423

424 Study limitations

425 To avoid the shivering with which an involuntary muscle contraction of immersed muscles can 426 increase metabolic demand (Proulx et al. 2003) and the associated alteration of NIRS profiles, we 427 set the water temperature of CWI and CCWI at $20^{\circ} \mathrm{C}$, a temperature at which subjects can easily 428 tolerate the cooling muscle treatment. Although we did not directly measure our subjects' shivering 429 response, there is only a slight possibility that shivering occurred in light of the subjects' thermal 430 sensations.

431 Compared to the more global information provided by blood flow in a large supplying artery, 432 the use of NIRS as a monitoring technique provides the ability to assess the specific effects on the 433 tissue of interest. NIRS cannot discriminate between myoglobin $(\mathrm{Mb})$ and hemoglobin $(\mathrm{Hb})$ 434 saturation or between arterial and venous compartments; thus, no unambiguous explanation can 435 be provided. Irrespective of the underlying reasons, the increase in tissue oxygenation that we 436 observed herein was a very consistent feature of the hemodynamic response to the compression of 437 resting muscle.

438

439 Athletic application of $\mathrm{CO}_{2}$-rich water immersion

440 Cold-water immersion is one of the beneficial recovery techniques that is commonly used by

441 athletes post-exercise to promote the restoration of body systems to baseline conditions and return

442 the physiological system to a pre-exercise state (Bleakley and Davison 2010). Our present 443 experiment was conducted with the subjects in a resting condition without a post-exercise state, 444 and thus the initial muscle blood flow at the onset of water immersion was quite different from 
445 that in the above-cited study of athletes. We thus conducted a second experiment to explore

446 whether this CCWI protocol at post-exercise is an effective intervention to maintain exercise

447 performance, which is associated with a reduced blood lactate concentration and reduced heart rate

448 (unpubl. data). Further research regarding the changes in oxygenation profiles following athletic

449 exercise is of interest.

450

451 CONCLUSION

452 Cold-water immersion with a rich $\mathrm{CO}_{2}$ concentration (CCWI) induced greater vasodilation in both

453 the gastrocnemius and tibialis anterior muscles, which represented apparent increased

$454 \Delta$ oxy $[\mathrm{Hb}+\mathrm{Mb}]_{\text {muscle }}$ during $\mathrm{CCWI}$ and/or $\Delta \mathrm{deoxy}[\mathrm{Hb}+\mathrm{Mb}]_{\text {muscle }}$ during the recovery period. Cold

455 water at $20^{\circ} \mathrm{C}$ does not dampen the local metabolic demand during CCWI. It is clear from the fact

456 that $\Delta$ deoxy $[\mathrm{Hb}+\mathrm{Mb}]_{\text {muscle }}$ is not reduced. Therefore, a significantly increased $\Delta \mathrm{StO}_{2}$ during CCWI

457 represented rich arterialized $\mathrm{O}_{2}$ content in the muscle tissue compared to CWI. Our results also

458 demonstrated that the lower $\mathrm{T}_{\mathrm{sk}}$ at the immersed lower extremity was associated with vasodilation

459 by $\mathrm{CO}_{2}$. The use of CCWI could continue to promote the heat transfer from the body to the water

460 after CCWI for $\leq 20 \mathrm{~min}$. 


\section{REFERENCES}

462 Aalkjær C, Peng H-L 1997. pH and smooth muscle. Acta Physiologica Scandinavica 161(4): 557-566.

463 Adami A, Koga S, Kondo N, Cannon DT, Kowalchuk JM, Amano T, Rossiter HB. 2015. Changes in whole 464 tissue heme concentration dissociates muscle deoxygenation from muscle oxygen extraction during passive 465 head-up tilt. Journal of Applied Physiology 118(9): 1091-1099 doi 10.1152/japplphysiol.00918.

466 Ando S, Hatamoto Y, Sudo M, Kiyonaga A, Tanaka H, Higaki Y. 2013. The effects of exercise under hypoxia 467 on cognitive function. PLoS One 8(5):e63630.

468 Bernjak A, Cui J, Iwase S, Mano T, Stefanovska A, Dwain L Eckberg DL. 2012. Human sympathetic outflows 469 to skin and muscle target organs fluctuate concordantly over a wide range of time-varying frequencies. The $470 \quad$ Journal of Physiology 590(2):363-375 doi 10.1113/jphysiol.2011.214528.

471 Binzoni T, Quaresima V, Barattelli G, Hiltbrand E, Gürke L, Terrier F, Cerretelli P, Ferrari M. 1998. Energy 472 metabolism and interstitial fluid displacement in human gastrocnemius during short ischemic cycles. Journal of Applied Physiology 85(4): 1244-1251.

474 Binzoni T, Quaresima V, Ferrari M, Hiltbrand E, Cerretelli P. 2000. Human calf microvascular compliance measured by near-infrared spectroscopy. Journal of Applied Physiology 88(2): 369-372.

Bleakley CM, Davison GW. 2010. What is the biochemical and physiological rationale for using cold-water immersion in sports recovery? A systematic review. British Journal of Sports Medicine 44(3): 179-187 doi 10.1136/bjsm.2009.065565.

Breemen C van, Farinas BR, Gerba P, McNaughton ED. 1972. Excitation-contraction coupling in rabbit aorta studied by the lanthanum method for measuring cellular calcium influx. Circulation Research 30(1): 4454.

482 Choo HC, Nosaka K, Peiffer JJ, Ihsan M, Abbiss CR. 2018a. Ergogenic effects of precooling with cold water immersion and ice ingestion: A meta-analysis. European Journal of Sport Science 18(2): 170-181 doi 10.1080/17461391.2017.1405077. 
485 Choo HC, Nosaka K, Peiffer JJ, Ihsan M, Yeo CC, Abbiss CR. 2018b. Peripheral blood flow changes in 486 response to postexercise cold water immersion. Clinical Physiology and Functional Imaging 38(1): 4655 doi: $10.1111 / \mathrm{cpf} .12380$.

488

489

490

491

492

493

494

495

496

497

498

499

500

501

502

503

504

505

506

507

508

Culver JP, Durduran T, Furuya D, Cheung C, Greenberg JH, Yodh AG. 2003. Diffuse optical tomography of cerebral blood flow, oxygenation, and metabolism in rat during focal ischemia. Journal of Cerebral Blood Flow \& Metabolism 23(8): 911-924 doi 10.1097/01.WCB.0000076703.71231.BB

Dahmane R, Djordjevic S, Simunic B, Valencic V. 2005. Spatial fiber type distribution in normal human muscle Histochemical and tensiomyographical evaluation. Journal of Biomechanics 38(12), 2451-2459 doi 10.1016/j.jbiomech.2004.10.020.

Davies RC, Eston RG, Poole DC, Rowlands AV, DiMenna F, Wilkerson DP, Twist C, Jones AM. 2008. Effect of eccentric exercise-induced muscle damage on the dynamics of muscle oxygenation and pulmonary oxygen uptake. Journal of Applied Physiology 105(5): 1413-1421.

De Roia G, Pogliaghi S, Adami A, Papadopoulou C, Capelli C. 2012. Effects of priming exercise on the speed of adjustment of muscle oxidative metabolism at the onset of moderate-intensity step transitions in older adults. American Journal of Physiology-Regulatory, Integrative and Comparative Physiology 302(10):R1158-R1166 doi 10.1152/ajpregu.00269.2011.

Diji A. 1959. Local vasodilator action of carbon dioxide on blood vessels of the hand. Journal of Applied Physiology 14(3): 414-416 doi 10.1152/jappl.1959.14.3.414.

Dodt E. 1956. Die Aktivitat der Thermoreceptoren bei nichtthermischen Reizen bekannter thermoregulatorischer Wirkung. Pflüger's Archiv für die gesamte Physiologie des Menschen und der Tiere 263(2): 188-200.

Dupont WD, Plummer WD. 1998. Power and Sample Size Calculations for Studies Involving Linear Regression. Controlled Clinical Trials 19: 589-601.

Fabiato A, Fabiato F.1978. E $\square$ ects of $\mathrm{pH}$ on the myofilaments and the sarcoplasmic reticulum of skinned cells from cardiac and skeletal muscles. Journal of Physiology 276: 233-255 doi 
10.1113/jphysiol.1978.sp012231.

510 Ferrari M, Muthalib M, Quaresima V. 2011. The use of near-infrared spectroscopy in understanding skeletal 511 muscle physiology: recent developments. Philosophical Transactions of the Royal Society A 369: 4577-

$512 \quad 4590$ doi $10.1098 /$ rsta.2011.0230.

513 Fukuda S, Matsumoto M, Nishimura N, Fujiwara N, Shimoji K, Takeshita H, Lee J-F.1990. Endothelial

514 modulation of norepinephrine-induced constriction of rat aorta at normal and high $\mathrm{CO}_{2}$ tensions. American 515 Journal of Physiology 258(4pt2): H1049-H1054 doi 10.1152/ajpheart.1990.258.4.H1049.

516 Gregson W, Black MA, Jones H, Milson J, Morton J, Dawson B, Atkinson G, Green DJ. 2011. Influence of cold 517 water immersion on limb and cutaneous blood flow at rest. American Journal of Sports Medicine 39(6): $518 \quad$ 1316-1323 doi: 10.1177/0363546510395497.

519 Gurevicius J, Salem MR, Metwally AA, Silver JM, Crystal GJ 1995. Contribution of nitric oxide to coronary $520 \quad$ vasodilation during hypercapnic acidosis. American Journal of Physiology 268: H39-H47.

521 Hartmann BR, Bassenge E, Pittler M.1997. E $\square$ ect of carbon dioxide-enriched water and fresh water on the 522 cutaneous microcirculation and oxygen tension in the skin of the foot. Angiology 48(4): 337-343. doi $10.1177 / 000331979704800406$.

524 Hensel H.1981. Thermal comfort in man. In: Hensel H (ed) Thermoreception and temperature regulation. $525 \quad$ Academic press: $168-184$.

526 Hickner RC, Fisher JS, Ehsani AA, Kohrt WM. 1997. Role of nitric oxide in skeletal muscle blood flow at rest and during dynamic exercise in humans. American Journal of Physiology 273(1 pt2): H405-H410 doi 10.1152/ajpheart.1997.273.1.H405

Hopkins WG, Marshall SW, Batterham AM, Hanin J. 2009. Progressive statistics for studies in sports medicine and exercise science. Medicine \& Science in Sports \& Exercise 41(1): 3-13 doi: 10. 1249/MSS.0b013e31818cb278.

532 Horiuchi M, Handa Y, Abe D, Fukuoka Y. 2016. Walking economy at simulated high altitude in human healthy 
533 young male lowlanders. Biology Open 5: 1408-1414 doi 10.1242/bio.019810.

534 Ihsan M, Watson G, Lipski M, Abbiss CR. 2013. Influence of postexercise cooling on muscle oxygenation and 535 blood volume changes. Medicine \& Science in Sports \& Exercise 45(4): 876-882 doi 10. 1249/ MSS. $536 \quad 0 \mathrm{~b} 013 \mathrm{e} 31827 \mathrm{e} 13 \mathrm{a} 2$.

537 Ihsan M, Watson G, Abbiss CR. 2016. What are the physiological mechanisms for post-exercise cold water 538 immersion in the recovery from prolonged endurance and intermittent exercise? Sports Medicine, 46(8), $539 \quad 1095-1109$.

540 IOS-7730 Moderate thermal environments- Determination of the PMV and PPD indices and specification of the $541 \quad$ conditions for thermal comfort. 1984.

542 Ishizaka H, Kuo L. 1996. Acidosis-induced coronary arteriolar dilation is mediated by ATP-sensitive 543 potassium channels in vascular smooth muscle. Circulation Research 78(1): 50-57 doi 10.1161/01.res.78.1.50.

Ito T, Moore JI, Koss MC. 1989. Topical application of $\mathrm{CO}_{2}$ increases skin blood flow. Journal of Investigative Dermatology 93:259-262 doi 10.1111/1523-1747.ep12277584.

547 Kellogg DL Jr. 2006. In vivo mechanisms of cutaneous vasodilation and vasoconstriction in humans during 548 thermoregulatory challenges. Journal of Applied Physiology 100(5): 1709-1718 doi 10.1152/japplphysiol.01071.2005

550 Koga S, Wüst RC, Walsh B, Kindig CA, Rossiter HB, Hogan MC. 2013. Increasing temperature speeds 551 intracellular $\mathrm{PO}_{2}$ kinetics during contractions in single Xenopus skeletal muscle fibers. American Journal of Physiology-Regulatory, Integrative and Comparative Physiology 304: R59-R66 doi10. 1152/ajpregu.00337.

554 Loutzenhiser R, Matsumoto Y, Okawa W, Epstein M. 1990. H+ induced vasodilation of rat aorta is mediated by 555 alterations in intracellular calcium sequestration. Circulation Research 67(2): 426-439 doi 10.1161/01.res.67.2.426. 
557 Mawhinney C, Jones H, Joo CH, Low DA, Green DJ, Gregson W. 2013. Influence of cold-water immersion on $558 \quad \operatorname{limb}$ and cutaneous blood flow after exercise. Medicine \& Science in Sports \& Exercise 45(12) 22772285 doi: 10.1249/MSS.0b013e31829d8e2e.

560 Partsch H, Winiger J, Lun B. 2004. Compression stockings reduce occupational leg swelling. Dermatologic Surgery 30(5): 737-743 doi 10.1111/j.1524-4725.2004.30204.x.

562 Proulx CI, Ducharme MB, Kenny GP. 2003. Effect of water temperature on cooling efficiency during 563 hyperthermia in humans. Journal of Applied Physiology 94(4): 1317-1323 doi 10.1152/japplphysiol.00541.2002. delivery-to-utilization mismatch at the onset of heavy-intensity exercise in optimally treated patients with CHF. American Journal of Physiology-Heart and Circulatory Physiology 297(5): H1720-H1728 doi: 10.1152/ajpheart.00596.2009.

Šrámek, P., Šimečková, M., Janský, L., Šavlíková, J., \& Vybíral, S. (2000). Human physiological responses to immersion into water of different temperatures. European Journal of Applied Physiology, 81(5), 436-442.

Stocks JM, Taylor NA, Tipton MJ, Greenleaf JE. 2004. Human physiological responses to cold exposure. Aviattion, Space, Environtal Medicine 75(5): 444-457.

Tansey EA, Johnson CD. 2015. Recent advances in thermoregulation. Advances in Physiology Education 39(3): 139-148 doi: 10.1152/advan.00126.2014.

Tobian L, Martin S, Eilers W. 1959. Effect of pH on norepinephrine-induced contractions of isolated arterial smooth muscle. American Journal of Physiology 196(5): 998-1002 doi 10.1152/ajplegacy.1959.196.5.998.

Truijen J, Kim YS, Krediet CT, Stok WJ, Kölgen RS, Colier WN, Secher NH, van Lieshout JJ. 2012. Orthostatic leg blood volume changes assessed by near-infrared spectroscopy. Experimental Physiology 97: 353-61 doi: 10.1113/expphysiol.2011.061051. 
581 muscle. Archives Internationales de Physiologie, de Biochimie et de Biophysique 76(1): 144-146.

582 White GE, Wells GD. 2013. Cold-water immersion and other forms of cryotherapy: physiological changes 583 potentially affecting recovery from high-intensity exercise. Extreme Physiology \& Medicine 2(1): 26 doi $584 \quad 10.1186 / 2046-7648-2-26$

585 Wolf S, Hardy JD. 1941. Studies on pain. Observations on pain due to local cooling and on factors involved in 586 the "cold pressor" effect. Journal of Clinical Investigation 20(5): 521-533 doi: 10.1172/JCI101245.

587 Yanagisawa O, Fukubayashi T. 2010. Diffusion-weighted magnetic resonance imaging reveals the effects of 588 different cooling temperatures on the diffusion of water molecules and perfusion within human skeletal 589 muscle. Clinical Radiology 65(11): 874-880 doi 10.1016/j.crad.2010.06.005.

590 Yamabata S, Shiraishi H, Munechika M, Fukushima H, Fukuoka Y, Hojo T, Shirayama T, Horii M, Matoba S,

591 Kubo T. 2016. Effects of electrical stimulation therapy on the blood flow in chronic critical limb ischemia 592 patients following regenerative therapy. SAGE Open Medicine 4:2050312116660723 doi 593 $10.1177 / 2050312116660723$. 


\section{Figure Legends}

595

596 Fig. 1. A subject immersing the right lower leg up to the knee for $15 \mathrm{~min}$ in $\mathrm{CO}_{2}$-rich cold water. 597

Fig. 2. The subjects' mean arterial pressure (MAP: A), heart rate (HR: B), core temperature $\left(\mathrm{T}_{\text {core }}\right.$ : C), and thermal sensation (D) values in the CCWI and CWI protocols. The mean and standard error values in $20 \mathrm{sec}$ are shown throughout the experiment. Blue circles: CWI at $20^{\circ} \mathrm{C}$. Red circles: CCWI at $20^{\circ} \mathrm{C}$.

602

Fig. 3. Mean values of skin temperature at the immersed leg $\left(\mathrm{T}_{\mathrm{sk}}-\mathrm{WI} ; \mathbf{A}\right)$ and non-immersed leg 604 ( $\mathrm{T}_{\mathrm{sk}}$-cont; B). Blue circles: CWI at $20^{\circ} \mathrm{C}$. Red circles: CCWI at $20^{\circ} \mathrm{C}$. Time effect from baseline 605 (BL): ${ }^{*} p<0.05,{ }^{* *} p<0.01$ vs. BL. Simple main effect: $\uparrow p<0.05, \dagger \uparrow p<0.01$ between CCWI and CWI 606 at the same time point.

607

Fig. 4. Changes of oxygenation (oxy $[\mathrm{Hb}+\mathrm{Mb}]$ ), deoxygenation (Deoxy $[\mathrm{Hb}+\mathrm{Mb}]$ ), and total 609 hemoglobin (total $[\mathrm{Hb}+\mathrm{Mb}]$ ) kinetics from the basal level in the superficial layer $(\mathbf{A}-\mathbf{C})$ and muscle layer (D-F) of the tibialis anterior (TA) muscle. Time effect from BL: ${ }^{*} \mathrm{p}<0.05,{ }^{*} \mathrm{p}<0.01$ vs. BL. Simple main effect: $\uparrow \mathrm{p}<0.05, \uparrow \uparrow \mathrm{p}<0.01$ between CCWI and CWI at the same time point.

612

613 Fig. 5. Changes of oxygenation (oxy $[\mathrm{Hb}+\mathrm{Mb}]$ ), deoxygenation (Deoxy $[\mathrm{Hb}+\mathrm{Mb}]$ ), and total

614 hemoglobin (total $[\mathrm{Hb}+\mathrm{Mb}]$ ) kinetics from the basal level in the superficial layer $(\mathbf{A}-\mathbf{C})$ and 615 muscle layer (D-F) of the gastrocnemius (GAS) muscle. Time effect from BL: ${ }^{*} \mathrm{p}<0.05,{ }^{* *} \mathrm{p}<0.01$ vs. BL. Simple main effect: $\uparrow \mathrm{p}<0.05, \uparrow \uparrow \mathrm{p}<0.01$ between CCWI and CWI at the same time point. 
618 Fig. 6. Changes of muscle oxygen saturation $\left(\Delta \mathrm{StO}_{2}\right)$ in TA muscle $(\mathbf{A}, \mathbf{C})$ and GAS muscle $(\mathbf{B}, \mathbf{D})$

619 between the CCWI and CWI. Time effect from BL: ${ }^{*} p<0.05,{ }^{*} p<0.01$ vs. BL. Simple main effect:

$620 \uparrow \mathrm{p}<0.05, \uparrow \uparrow \mathrm{p}<0.01$ between CCWI and CWI at the same time point. 
Figure 1

Photograph of $\mathrm{CO}_{2}$-rich cold water immresion

Photograph of a subject immersing the right lower leg up to the knee for 15 min in $\mathrm{CO}_{2}$-rich cold water.

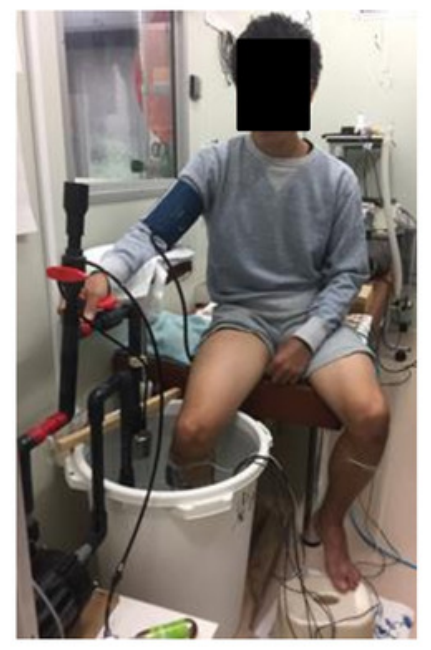


Figure 2

The subjects' mean arterial pressure, heart rate, core temperature, and visual anagoge scale.

Fig. 2. The subjects' mean arterial pressure (MAP: A), heart rate (HR: B), core temperature (Tcore: C), and visual anagoge scale (VAS: D) values in the CCWI and CWI protocols. Mean values in $20 \mathrm{sec}$ and standard error are shown throughout the experiment. Blue circles: CWI at $20^{\circ} \mathrm{C}$. Red circles: $\mathrm{CCWI}$ at $20^{\circ} \mathrm{C}$.

A

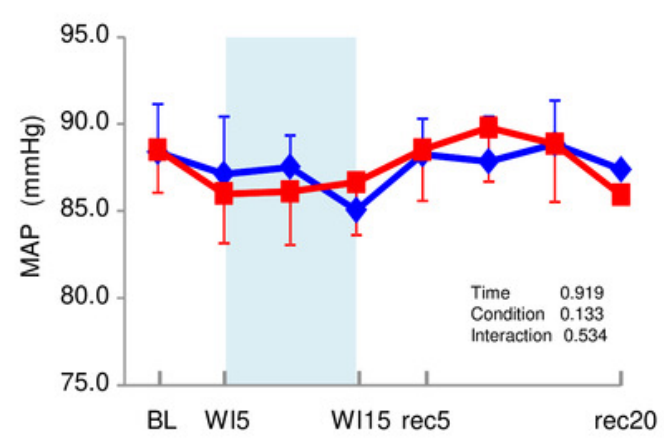

C

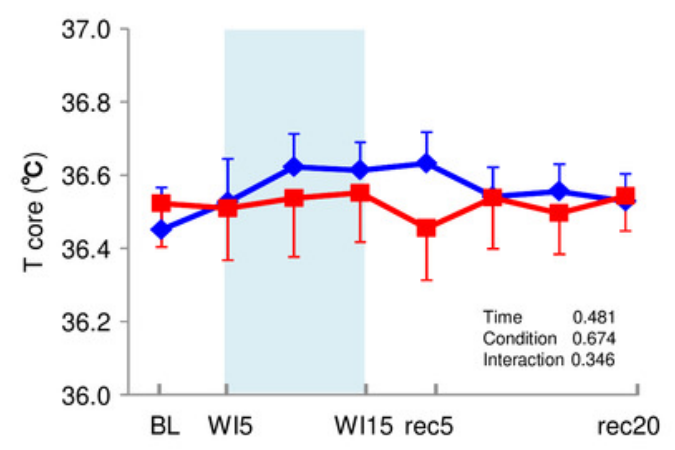

B
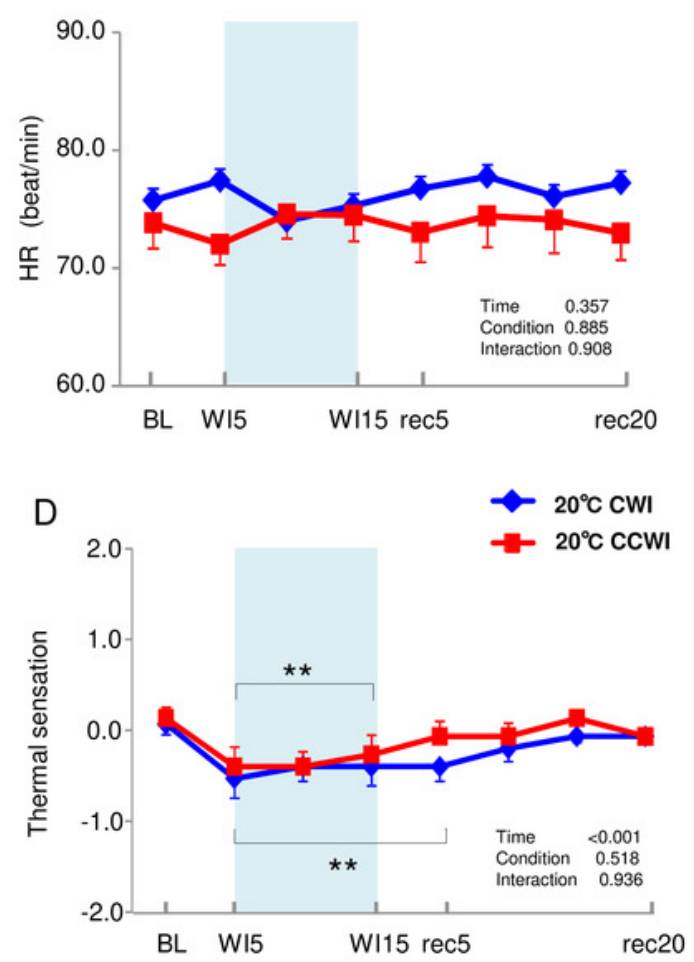
Figure 3

The subjects' skin temperature at the immersed leg and non-immersed leg.

Fig. 3. Mean values of skin temperature at the immersed leg (Tsk-Wl; A) and non-immersed leg (Tsk-cont; B). Blue circles: $\mathrm{CWI}$ at $20^{\circ} \mathrm{C}$. Red circles: $\mathrm{CCWI}$ at $20^{\circ} \mathrm{C}$. Time effect from baseline: $* p<0.05,{ }^{* *} p<0.01$ from BL. Simple main effect: $t p<0.05,+t p<0.01$ between CCWI and $\mathrm{CWI}$ at the same time point.
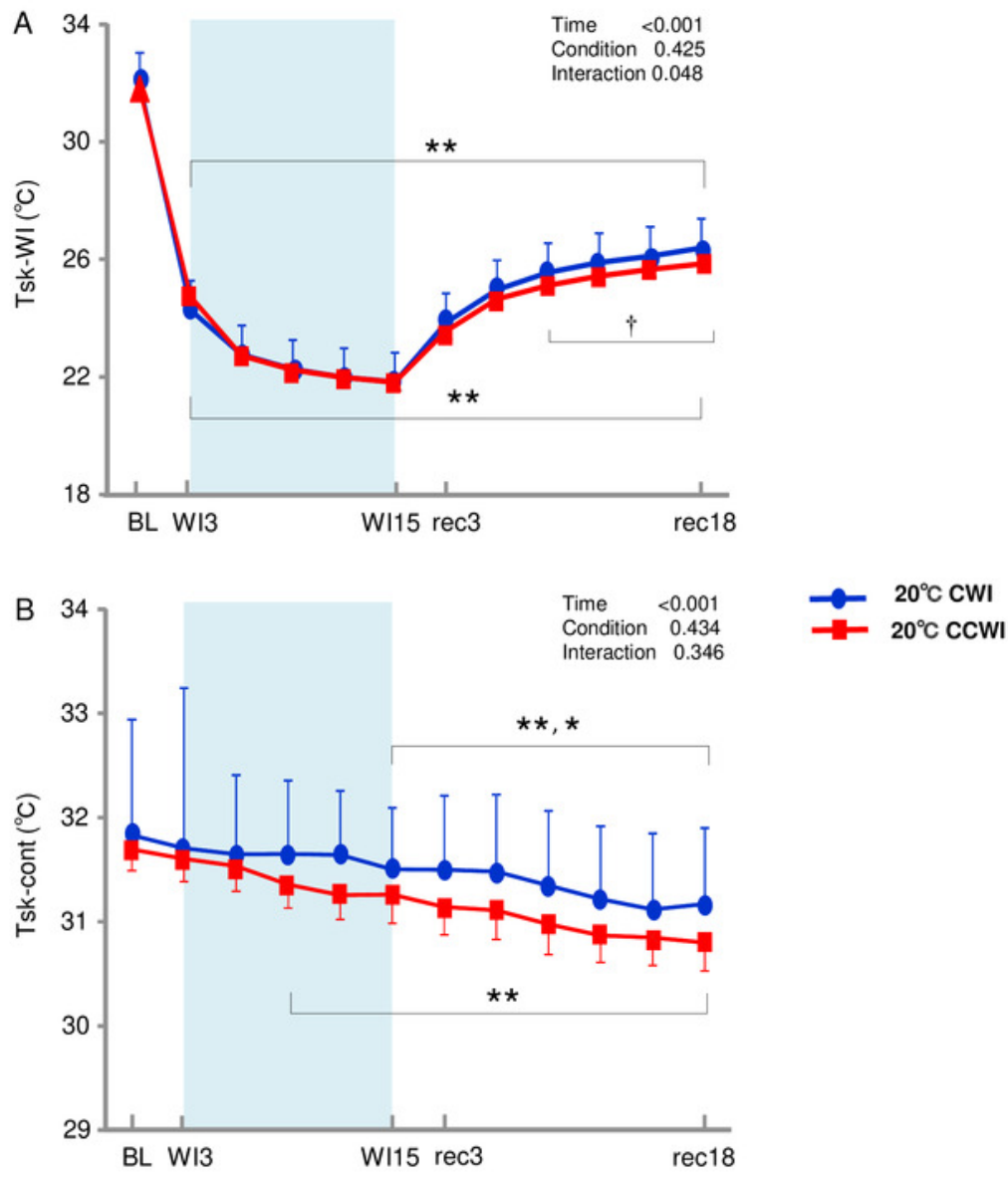
Figure 4

Changes of oxygenation, deoxygenation, and total hemoglobin kinetics in the tibialis anterior muscle.

Fig. 4. Changes of oxygenation (oxy $[\mathrm{Hb}+\mathrm{Mb}]$ ), deoxygenation (Deoxy $[\mathrm{Hb}+\mathrm{Mb}]$ ), and total hemoglobin (total $[\mathrm{Hb}+\mathrm{Mb}]$ ) kinetics from the basal level in the superficial layer $(\mathbf{A}-\mathbf{C})$ and muscle layer (D-F) of the tibialis anterior (TA) muscle. Time effect from baseline: ${ }^{*} p<0.05$, ${ }^{* *} \mathrm{p}<0.01$ from BL. Simple main effect: $\mathrm{tp}<0.05, \mathrm{ttp}<0.01$ between CCWI and CWI at the same time point. Time bins and symbols are the same as in Fig. 3.

TA superficial
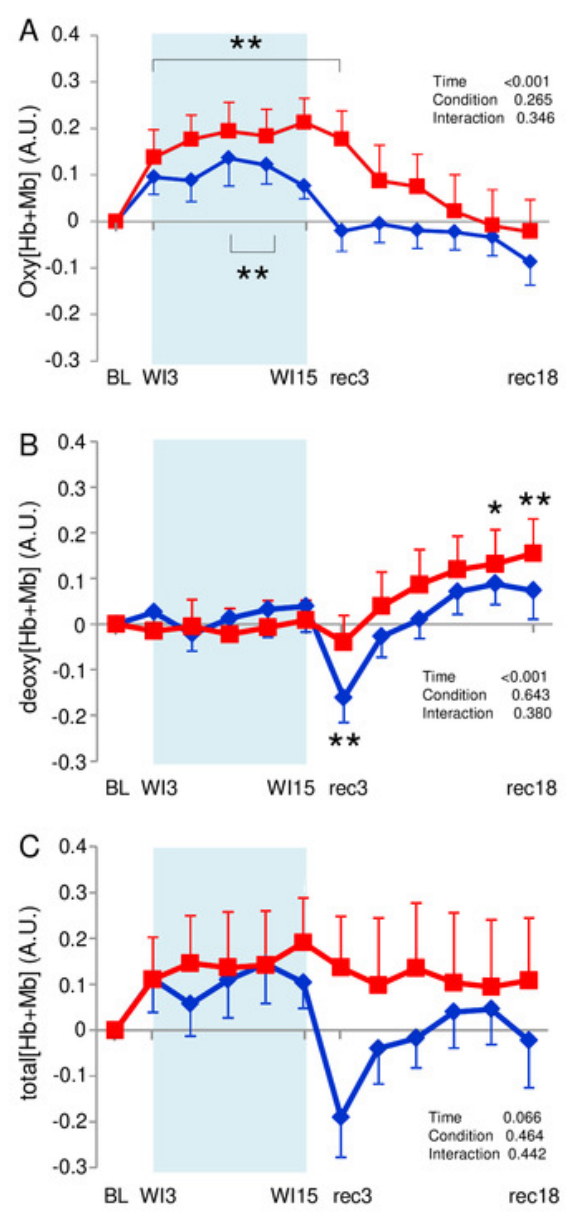

TA muscle
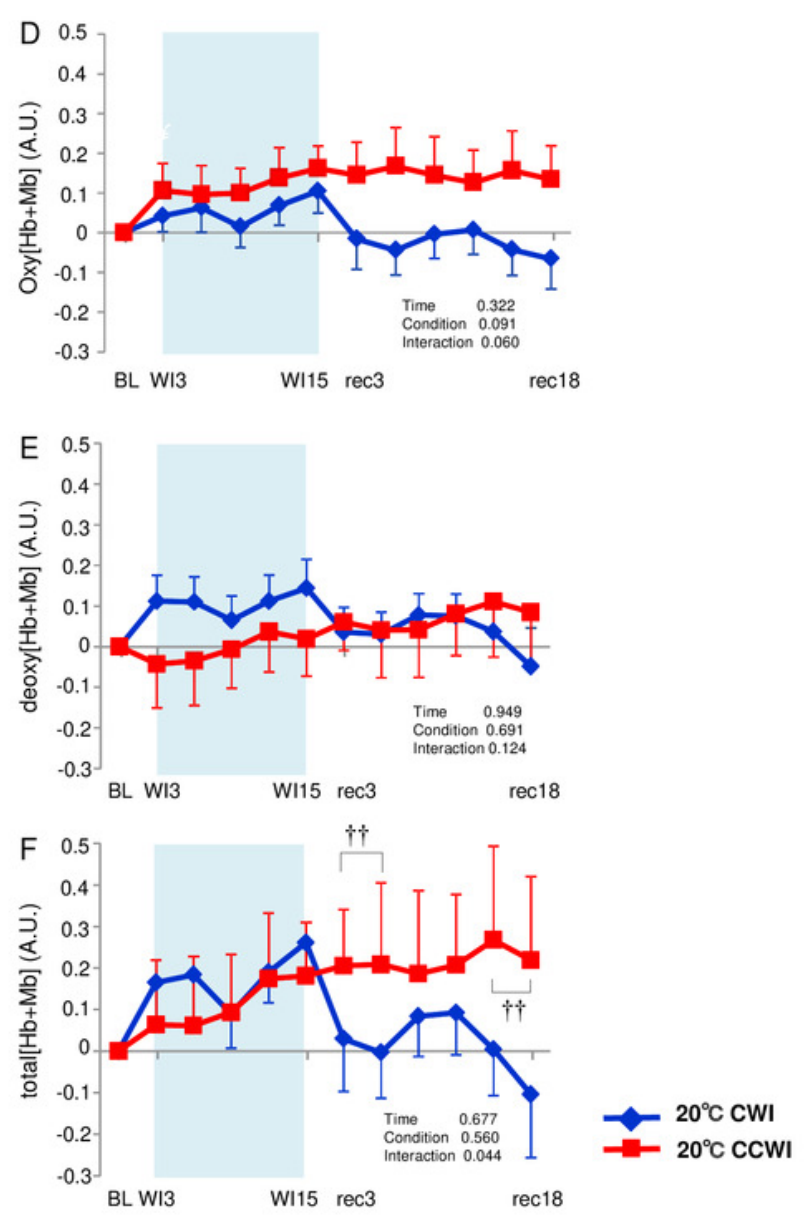
Figure 5

Changes of oxygenation, deoxygenation, and total hemoglobin (total $[\mathrm{Hb}+\mathrm{Mb}]$ ) kinetics in the gastrocnemius (GAS) muscle.

Fig. 5. Changes of oxygenation (oxy $[\mathrm{Hb}+\mathrm{Mb}]$ ), deoxygenation (Deoxy $[\mathrm{Hb}+\mathrm{Mb}]$ ), and total hemoglobin (total $[\mathrm{Hb}+\mathrm{Mb}]$ ) kinetics from the basal level in the superficial layer $(\mathbf{A}-\mathbf{C})$ and muscle layer (D-F) of the gastrocnemius (GAS) muscle. Time effect from baseline: ${ }^{*} p<0.05$, ${ }_{* *} p<0.01$ from BL. Simple main effect: $\uparrow p<0.05,+\dagger p<0.01$ between CCWI and CWI at the same time point. Time bins and symbols are the same as in Fig. 3.
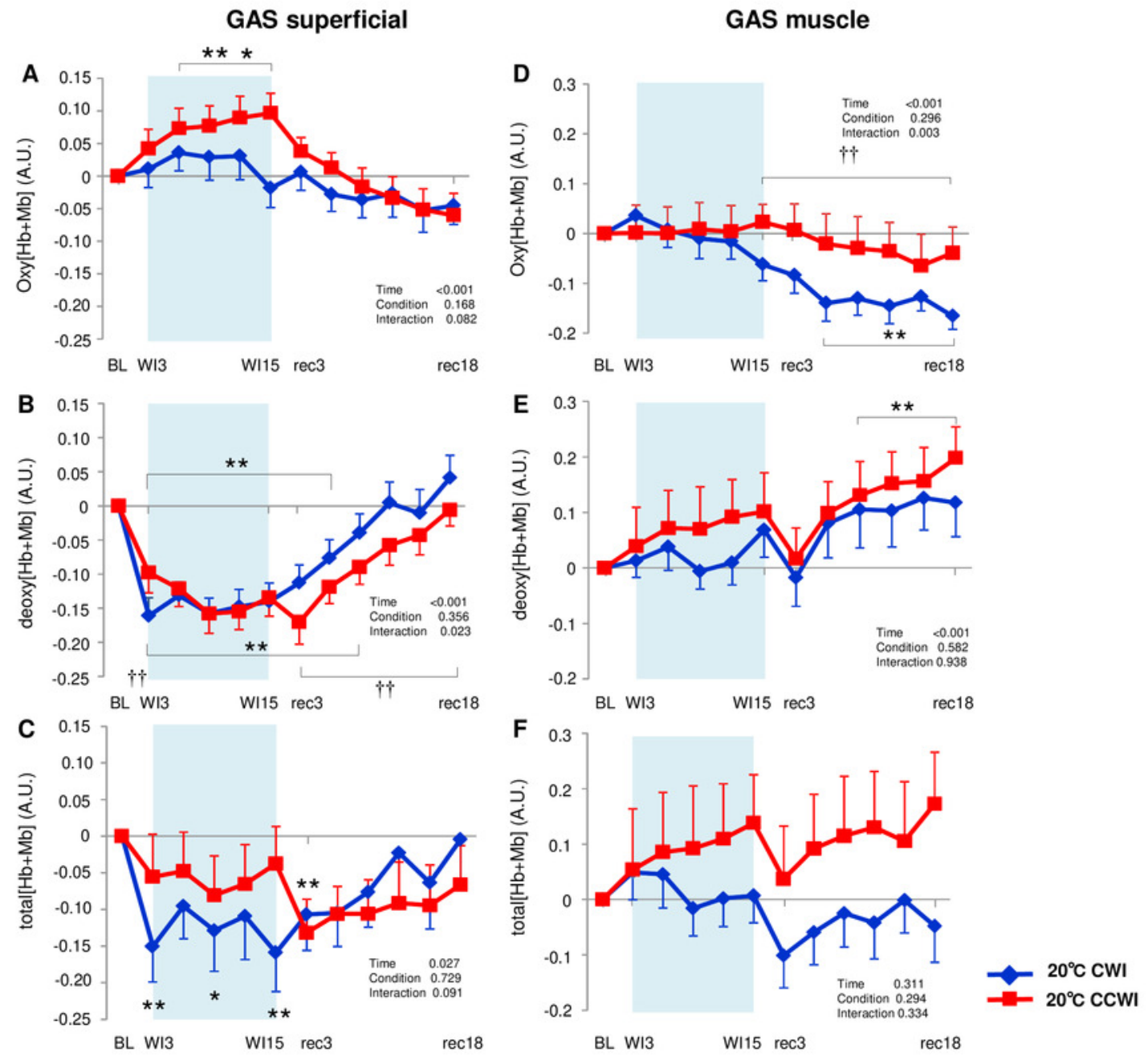
Figure 6

Changes of muscle oxygen saturation $\left(\Delta \mathrm{StO}_{2}\right)$ in TA muscle and GAS muscle between the CCWI and CWI.

Fig. 6. Changes of muscle oxygen saturation $\left(\Delta \mathrm{StO}_{2}\right)$ in TA muscle $(\mathbf{A}, \mathbf{C})$ and $\mathrm{GAS}$ muscle (B,D) between the CCWI and CWI. Time effect from baseline: $* p<0.05$, **p<0.01from BL. Simple main effect: $\dagger p<0.05,+\dagger p<0.01$ between CCWI and CWI at the same time point. Time bins and symbols are the same as in Fig. 3 .
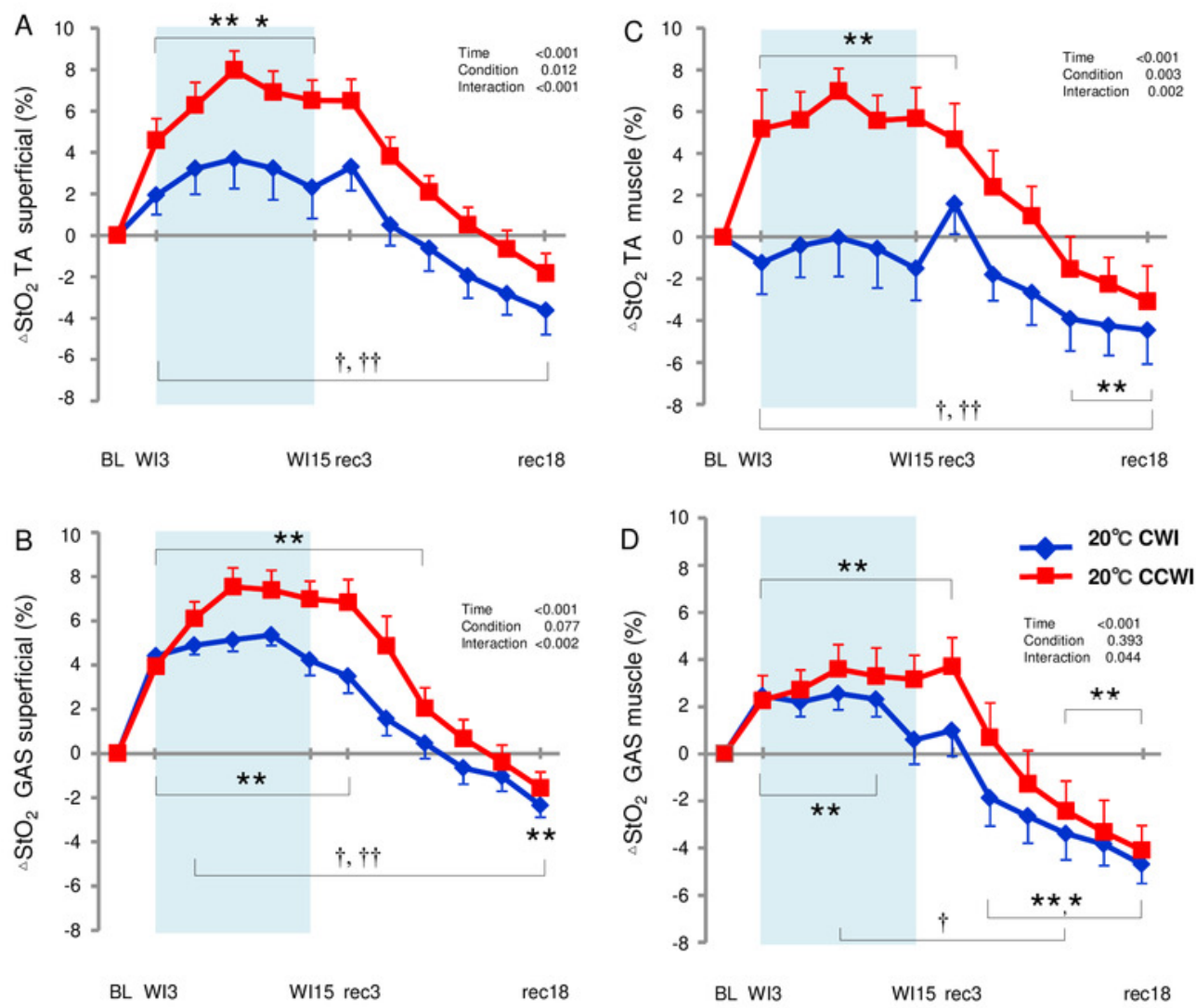

$\begin{array}{lll}\text { BL WI3 WI15 rec3 } & \text { rec18 }\end{array}$ 